\title{
SOBRE A AMIZADE EM TEMPOS DE SOLIDÃO
}

\author{
Lívia Godinho Nery Gomes \\ Universidade de São Paulo, São Paulo, Brasil \\ Nelson da Silva Junior \\ Universidade de São Paulo, Université de Bretagne Occidentale \\ e Instituto Sedes Sapientiae, São Paulo, Brasil
}

RESUMO: O presente artigo analisa alguns resultados de uma pesquisa de mestrado que investigou as semânticas da amizade e analisou a qualidade política da amizade. O artigo tem como objetivo descrever e discutir as implicações da decomposição dos laços públicos e o conseqüente aniquilamento do exercício político. No líquido cenário da atualidade, os processos de individualização e da fragilidade dos laços configuram a decomposição do espaço público e o conseqüente rebaixamento da política. O mercado capitalista, ao transformar vínculos humanos e pessoas em mercadorias, tem promovido o esfacelamento da solidariedade humana e das habilidades de sociabilidade. Nesta pesquisa foram entrevistados trabalhadores de cooperativas populares sobre as suas histórias de amizade. Os resultados dessa pesquisa destacam que os laços de amizade podem compor relações de acolhimento e comprometimento com o outro, nas quais se vive o vigor da solidariedade. Não obstante, as narrativas dos sujeitos também revelaram a contemporânea fragilidade dos laços sociais, o isolamento social e o individualismo.

PALAVRAS-CHAVE: Amizade; sociabilidade; fragilidade dos laços; individualismo.

\section{ABOUT FRIENDSHIP IN TIMES OF SOLITUDE}

ABSTRACT: This paper analyzes some results of a research that investigated the semantics on friendship and analyzed the political quality of the friendship. The objective of this article is to describe and to argue the implications of the decomposition of public bonds and the consequent destruction of political engagement. In the liquid scene of current times, individualization process and the weakening of social bonds configures the decomposition of public space and the consequent degradation of politics. The capitalist market when transforming human bonds and people into merchandise, has promoted the fragmentation of human solidarity and the abilities of sociability. In this research workers of a popular cooperative were interviewed on the histories of their friendships. The results of this research highlight that the bonds of friendship can form relations of shelter and commitment with the other, in which one lives the vigor of solidarity. On the other hand, the narratives of the citizens had also disclosed the contemporary fragility of social bonds, social isolation and individualism.

KEYWORDS: Friendship; sociability; fragility of bonds; individualism.

O presente artigo tem como objetivo analisar as relações de amizade na atual rede de sociabilidade, no contexto de economia neoliberal que tem maximizado o individualismo e suas nefastas consequiências nos sujeitos contemporâneos que mais do que nunca vivenciam extrema solidão mesmo em meio às multidões das grandes cidades. Imersos em suas "redomas solitárias", os sujeitos nunca estiveram tão ávidos por relacionar-se, não obstante, a marca dos relacionamentos contemporâneos tem sido a ambigüidade do desejo de estreitar os laços e, ao mesmo tempo, mantê-los frouxos. É sobre essa contemporânea fragilidade dos vínculos humanos e a insegurança e desejos conflitantes inspirados por ela que este artigo busca registrar e apreender.

Na contemporaneidade, a desvairada velocidade da lógica produtiva do mercado capitalista globalizado é impressa no andar das pessoas apressadas cujos olhares evasivos e fugidios já não se cruzam, movidas pelo imperativo de sucesso particular a qualquer custo. Em tempos nos quais a economia capitalista engendra exaustivas cargas de trabalho que ampliam o tempo das tradicionais jornadas do trabalhador, cansando corpos, afastando as pessoas, dispersando amigos voltar a atenção para a intersubjetividade, para amizade, torna-se mais do que uma inegável urgência, representa a possibilidade de despertar e questionar modos de letargia.

A percepção de que a preocupação exclusiva com interesses individuais não satisfaz revela o sofrimento sentido pela escassez de contato humano - que é, em si mesmo, a condição que nos faz humanos - o fato de estarmos neste mundo com outros, que Arendt (2001) tanto ressalta.

Essa presente conjuntura em que a necessidade mais urgente persiste a ser a necessidade de relacionar-se faz com que Bloom (1993) perspicazmente denuncie que:

... a necessidade mais insistente hoje em dia, das pessoas em geral e dos jovens em particular, continua a ser a necessidade de ligação humana, uma ligação que transcenda o isolamento do egoísmo 
pessoal e em que o pensar sobre si próprio se encontre inextricavelmente ligado com o pensar sobre um outro (Bloom, 1993, p. 14).

Bauman (2004) também demonstra categoricamente que no líquido cenário da atualidade, são os relacionamentos que melhor representam os agudos e desconcertantes sentidos da ambivalência. A contemporânea fragilidade dos laços humanos produz sentimento de insegurança que incute desejos e sentimentos ambíguos de estreitamento e frouxidão dos laços ao mesmo tempo. Diante da precariedade nos relacionamentos e do contexto de individualização, há um esforço por relacionar-se, porém os relacionamentos a longo prazo que envolvem parcerias, compromisso e engajamento mútuo são vistos com desconfiança e ameaça.

Ao procuramos atenciosamente refletir sobre a amizade na contemporânea trama das relações cotidianas, com interesse em sua dimensão política, esta pesquisa buscou compreender a amizade em sua qualidade de experimentação política.

Procuramos compreender as relações de amizade à luz das narrativas de trabalhadores de cooperativas populares, ao concebermos o cooperativismo como interessante campo de investigação da qualidade de experimentação política da amizade, pois a economia solidária também constitui resistência à economia capitalista, configurando uma nova concepção de trabalho pautado em relações horizontais e solidárias - como ilumina a amizade, visando superar o desemprego e a exclusão social engendrados pelo modelo capitalista.

O cooperativismo, tal como informa a qualidade política da amizade, também pressupõe um espaço dialogante aberto à experimentação, pois o modo de ser da cooperativa é discutido e determinado coletivamente pelos cooperados em assembléias nas quais todos têm direito a voto o que requer negociações e acordos num contexto de igualdade política, como ilumina a amizade.

\section{Amizade e contemporaneidade: laços frágeis, naufrágios urbanos}

Vários diagnósticos descrevem o mundo contemporâneo como uma época marcada por um forte individualismo em nosso convívio social, predominando um enfraquecimento na negociação de interesses comuns. Bauman (2001), por exemplo, indica o surgimento de uma nova categoria na sociabilidade contemporânea, aquela de espaços "públicos, mas não civis" cuja principal característica "é a dispensabilidade de interação".

O contemporâneo esvaziamento do espaço público e o conseqüente rebaixamento político retratam a sociedade do consumo na qual as preocupações e motivações sociais estão voltadas para os interesses individuais e privados, configurando a decadência do engajamento político e dos interesses coletivos. Bauman (2001), ao falar dos processos de individualização e desintegração dos laços públicos como marcas da contemporaneidade, aponta essa primazia do privado e o aniquilamento do sentido de público.

Segundo Bauman (2001) essa decomposição do espaço público - terreno natural do político - configura-se por uma decadência do diálogo e da arte de negociar interesses comuns gerando uma patologia da política fundada na fluidez/fragilidade dos laços humanos que substitui o compromisso mútuo e a comunicação pelo distanciamento do outro, evitando-se a necessidade de contato e negociação. Essa técnica do desvio do "não fale com estranhos" é apontada por Bauman (2001) como marca da precarização política contemporânea e enfraquecimento dos laços e parcerias que "tendem a ser vistos e tratados como coisas destinadas a serem consumidas, e não produzidas" (Bauman, 2001, p. 187).

Segundo Sennett (1988) “a visão intimista é impulsionada na proporção em que o domínio público é abandonado, por estar esvaziado" (p. 26). O espaço público aqui entendido a partir da noção arendtiana: espaços coletivos de embates com a multiplicidade, a diferença, que produzam a vontade de agir desconstruindo formas fixas de sociabilidade - torna-se destituído de sentido, predominando um enfraquecimento das parcerias e laços humanos, uma debilitação da capacidade criativa das pessoas, através de diversos dispositivos de uma subjetividade compreendida e investida ao nível do individual, do âmbito da privacidade.

Esse autor, ao destacar o esvaziamento e despolitização do espaço público típicos da sociedade intimista, também ressalta a primazia do narcisismo nas relações sociais, sendo a experiência de abertura para os outros sentida como destrutiva. Inserida nessa lógica familialista e intimista da sociedade, a amizade encontra-se diluída em seu sentido de experimentação voltada para o mundo no sentido arendtiano de espaço público e político. Pode-se dizer que as relações de amizade, no atual contexto de individualismo em que as relações com os outros (em sua diferença/estranheza) são sentidas com medo e desconfiança, tornam-se espaços destituídos de experimentação do não-familiar, constituindo-se com a essência do que Sennett (1988) chama de "celebração do gueto".

Configurando-se nessa lógica de "celebração do gueto", as relações de amizade perdem a beleza da experiência política, apontada por Arendt (1993), de alargamento de opiniões no encontro com o outro, na qual é possível viver o sentimento inquietante e desestabilizador do questionamento de crenças e opiniões familiares, num movimento de "descolamento" do familiar que permite um deslocamento para ver o mundo no lugar dos outros. A "celebração do gueto" visa tornar a experiência humana íntima e familiar, sobrepujando o desconhecido, apagando as diferenças, conforme destaca Sennett (1988): 
Aquilo que precisamente se perde com essa celebração é a idéia de que as pessoas só podem crescer através de processos de encontro com o desconhecido. Coisas e pessoas que são estranhas podem perturbar idéias familiares e verdades estabelecidas; o terreno não familiar tem uma função positiva na vida de um ser humano. Essa função é a de acostumar o ser humano a correr riscos. $O$ amor pelo gueto, especialmente o gueto de classe média, tira da pessoa a chance de enriquecer as suas percepções, a sua experiência, e de aprender a mais valiosa de todas as lições humanas: a habilidade para colocar em questão as condições já estabelecidas de sua vida (Sennett, 1988, p. 359-360).

Segundo Bauman (2001) nos lugares de consumo que se caracterizam pela dispensabilidade da interação, o significado mais profundo da idéia de "comunidade" é reduzido ao sentimento de que "somos semelhantes" e que todos são movidos e guiados pelos mesmos motivos. Portanto, essa "comunidade" caracteriza-se pela substituição do compromisso mútuo pelas técnicas de desvio e de evasão que não envolvem negociações.

\section{Metodologia}

$\mathrm{Na}$ escolha dos interlocutores, optou-se por trabalhadores de cooperativas, pois o cooperativismo é em si mesmo uma forma de organização social e econômica que busca a superação das lógicas e práticas excludentes inerentes ao capitalismo (Singer, 2002). Ou seja, o cooperativismo configura uma organização de resistência, que busca desnaturalizar o capitalismo, buscando superar seus graves efeitos sociais, como o desemprego, por exemplo, sendo fundamentado pela economia solidária a qual, de acordo com Singer, pressupõe a associação em que há igualdade política - condição que a amizade informa, em vez do contrato entre desiguais em que há competição e dominação política.

Além da necessidade de igualação política - aquilo que a amizade ilumina segundo Singer (2002), a economia solidária também requer a autogestão, ou seja, pressupõe uma administração democrática, num contexto de cooperação, suscitando um espaço dialogante e de solidariedade - condições que a amizade emana, configurando uma maneira de produção baseada na ajuda mútua, a qual, muitas vezes, pode surgir a partir da iniciativa e união de amigos contra o desemprego, na luta pela sobrevivência, pela dignidade. É nesse sentido que a cooperativa é uma organização que reconhece que sua força está na participação e comunicação, que tem como princípios básicos a cooperação e a solidariedade, como espaço dialogante indissociável de um posicionamento político por parte de seus trabalhadores que estes representam sujeitos privilegiados para a investigação da relação de amizade como espaço de experimentação política.
Esta pesquisa foi desenvolvida com trabalhadores de cooperativas populares na Universidade de São Paulo (USP). Os dados provêm da participação no cotidiano de três cooperativas durante o período de um ano, registrada em diário de campo, e da análise das sessões de entrevistas com os cooperados. ${ }^{1}$ Todos os sujeitos entrevistados são adultos com faixa etária maior que 20 anos e moram em bairros periféricos de São Paulo.

Antes de começar a etapa da entrevista propriamente dita, houve um período no qual se acompanhou o cotidiano de cada uma dessas cooperativas para informar sobre a pesquisa e para conhecer os cooperados participando, na medida do possível, de espaços de reunião e acompanhando o trabalho de alguns deles, momentos que foram relatados em diário de campo. Portanto, as primeiras entrevistas só foram realizadas após um certo tempo de convivência com os cooperados e quando eles mesmos apontaram o momento de realização dessas, solicitandome para entrevistá-los.

Este trabalho utilizou a descrição etnográfica como metodologia interpretativa das narrativas de amizades. As histórias de amizade foram relatadas em sessões de entrevistas nas quais as perguntas se configuraram apenas como um iniciador para um espaço de conversas. Esta relação comunicativa na qual o sujeito entrevistado não é tomado como alvo, mas como interlocutor, implica um encontro cuidadoso de dedicação no testemunho dos outros, no gosto pela opinião do outro - como informa a amizade (Arendt, 1993, 2001).

Bosi (2003) compreende a entrevista como um encontro atencioso que envolve responsabilidade pelo outro e "deve durar quanto dura uma amizade". Conforme ressalta Bosi: "a entrevista ideal é aquela que permite a formação de laços de amizade; tenhamos sempre na lembrança que a relação não deveria ser efêmera" (p. 60). Portanto, a entrevista conforme compreende Bosi constitui um encontro no qual o depoente não é tomado como alvo de interpretações, mas como intérprete, ele mesmo, através de suas narrativas de amizades.

De acordo com a descrição etnográfica, os discursos de amizades dos sujeitos são entendidos com narrativas de significados - tal como compreendem Bruner (1986) e Geertz (1989). Segundo Bruner, estruturas narrativas servem como guias interpretativos, elas nos dizem o que constitui dados, definem tópicos de estudo e identificam uma construção na situação de campo que as transformam do estranho para o familiar.

Nesse sentido, as narrativas de amizades dos sujeitos desta pesquisa iluminam as semânticas da amizade bem como contribuem para elucidar a qualidade política da amizade. Estas narrativas contemporâneas dão significado à experiência da amizade, além de produzirem novos vocabulários e sentidos - como compreendem Bruner (1986) e Geertz (1989). 


\section{Resultados e discussão}

\section{"Convivência afastada"}

A semântica que significa o amigo como íntimo circunscreve a amizade num universo familiar, conhecido, habitual. Em geral, a rede de amigos dos sujeitos entrevistados se configurava entre pessoas que compartilhavam espaços em comum: bairro, escola, trabalho. Na maioria dos relatos os amigos eram do mesmo nível socioeconômico. Essa articulação amizade-intimidade-proximidade acaba privilegiando as afinidades e não as diferenças, ou seja, é o que existe em comum, a semelhança que se torna imperativa, remetendo a uma lógica individualista.

Não é novidade que vivemos em um país de exorbitante estratificação social, no qual há uma extrema discrepância entre as classes sociais, sendo classificado entre os países com maiores desigualdades sociais. As relações de amizade estabelecidas no ambiente comum, familiar reproduzem essa lógica estratificada das classes sociais, pois os amigos relatados são sempre da mesma situação socioeconômica. Ao conversar com Pedro, ele relata em entrevista essa dificuldade de amizade entre pessoas de classes sociais diferentes. Pedro mora num bairro periférico da zona oeste de São Paulo e conta com bastante pesar que a imagem do pobre encontra-se "destruída", segundo ele porque existe uma generalização do que acontece na periferia, ficando a "convivência afastada".

\begin{abstract}
... se você tiver uma amizade assim, o cara que é bem sucedido da vida e um cara que tem um baixo nível, é pobre e você ser amigo de umas pessoas dessas assim, fica muito difícil [grifo nosso], mas, eu acredito que tem amizades assim, mas é meio diferente... a gente vê muitos casos hoje em dia que é assim, a sociedade pobre está muito, a imagem está muito destruída por causa do que acontece na periferia do que acontece com as pessoas pobres, o erro que elas fazem, é, generalizam todo mundo, todo mundo que mora, a classe média muito baixa, então, é que nem eu te falei, a convivência fica afastada, é raro você ver essas amizades hoje em dia... [grifo nosso] (Pedro).
\end{abstract}

Em outros momentos de nossas conversas, Pedro também narra, com um certo lamento, a história de um amigo que jogava bola com ele no mesmo campo de terra batida e depois que conseguiu se profissionalizar entrando no time do São Paulo e "mudou de vida", afastou-se, chegando a estar no mesmo local que Pedro e não cumprimentá-lo, fingindo que o esqueceu. Esta relação entre amizade e diferenças sociais aparece de forma bastante destacada e é tão marcante que Pedro diz ficar até emocionado quando conta a história de um outro amigo que tinha melhores condições econômicas e o ajudou a aprender a nadar. As amizades íntimas, próximas estabelecidas entre pessoas de ambiente familiar dificultam a possibilidade de experimentar o surpreendente (como o aprender a nadar para Pedro) que o contato com a alteridade permite. Ainda, essa linguagem familiar ajuda-nos a compreender e esclarecer a maneira como se formam e reforçam as estratificações sociais.

\section{Solidariedade esmorecida: o convívio destruído ou o esvaecer da humanidade}

A beleza encantadora do gesto de hospitalidade - que segundo Derrida e Dufourmantelle (2003) só pode ser poético - é sentida com atributo de escassez no atual cenário de liquefação das relações onde a figura do estrangeiro/desconhecido é sempre vista como ameaça. Pedro afirma em seu relato a dificuldade de experimentação, nos dias atuais, do que ele viveu com Jasmim (amiga que o acolheu quando ele foi ao Rio de Janeiro pela primeira vez). Pedro fala da apreensão das pessoas diante do não familiar e destaca que entre desconhecidos não há envolvimento. Quando retomei essa estória da amiga Jasmim na segunda sessão de entrevista, Pedro diz que a sentiu como uma experiência diferente, como uma experiência nova:

... é como eu falei da outra vez, experiência diferente, de chegar num lugar, e uma pessoa se interessar, te ajudar [grifo nosso], é uma experiência nova, tipo se alguém chega aqui novato assim, fica meio perdido, tipo você guiar a pessoa, orientar e instruir como é que é lugar, tal, o que você pode fazer, o que você não deve fazer que vai incomodar outros moradores ou o local, de ir pra balada como que faz, a hora que tem que chegar, aí do mesmo jeito eu aprendi e quando eu vou hoje lá eu sei os lugares aonde eu vou, então, me influenciou a fazer o mesmo e conhecendo o lugar agora que eu freqüento, os lugares que eu freqüento lá quando eu vou, aí já tem a medida certa de tempo e horário, os cuidado que tenho que ter, tudo mais (Pedro).

O receio da aproximação entre as pessoas, destacado por Pedro, articula-se ao contexto atual de impulso na direção de um ambiente uniforme, no qual os vínculos são estabelecidos na imediação, havendo um crescente recuo da alteridade, uma ampliação da recusa de enfrentamento com a diferença e o subsequiente atrofiamento das habilidades sociais que este requer. Sobre esse afastamento da alteridade, próprio de uma sociabilidade estratificada Bauman (2004) constata a atual dificuldade de tratar um estranho com solidariedade:

Já que esqueceram ou não se preocuparam em adquirir as habilidades necessárias pra viver com a diferença, não surpreende muito que essas pessoas vejam com um horror crescente a possibilidade de se confrontarem face a face com estranhos. Estes tendem a parecer ainda mais assustadores na medida em que se tornam cada vez mais diferentes, exóticos e incompreensíveis, e em que o diálogo e a interação que poderiam acabar assimilando sua 'alteridade' 
se diluem ou nem chegam a ter lugar. O impulso que conduz a um ambiente homogêneo e territorialmente isolado pode ser disparado pela mixofobia, mas praticar a separação territorial significa preservá-la e alimentá-la (Bauman 2004, p. 135).

Essa contemporânea dificuldade de tratar um estranho com humanidade, sobre qual Bauman (2004) nos alerta, aparece em um outro relato de Pedro, quando ele fala da resistência de abertura para o outro, apontando que o se aproximar de alguém é vivido como uma situação aflitiva, na qual o abordar uma pessoa é uma experiência permeada de constrangimento e receio. A aproximação entre pessoas é sentida como um risco, o que legitima e reforça o atrofiamento dos laços de amizade e parcerias - como destaca Pedro:

... você vai tipo no parque do Ibirapuera, vamos comparar uma paquera, por exemplo, você está olhando pra uma menina, quer conhecer a menina, você vai chegar na pessoa e às vezes vai falar assim, eu quero te conhecer, às vezes até a pessoa está interessada na pessoa, de conversar e tudo mais, mas não se aproxima porque vai pensar que pode ser um cara bagunceiro, vagabundo, coisa parecida, assim, então, hoje é muito difícil você chegar num local fazer amizades assim, fácil assim, até a confiança da pessoa até onde vai, se às vezes você não confia, você às vezes também não tem amigo, então você tem que ter esse primeiro passo, esse primeiro passo de tipo ser inseguro, mas sem ser, ou seja, você tem que ir lá e conferi pra ver se é aquilo, se não for aí você corre esse risco. É muito difícil você chegar num lugar e conhecer a pessoa, sem saber o que ela faz, o que ela deixa de fazer, e dar certo assim, às vezes você conversar e criar uma amizade, tudo mais, eu acho que tem vários fatores que às vezes impedem, esse lado de fazer esse laço de amizade (Pedro).

Essa apreensiva aproximação entre pessoas estranhas, desconhecidas impede a formação de novos laços de amizade, como Pedro afirma, precisamente daqueles que não se estabelecem em ambiente de imediação, o que torna as pessoas cada vez mais desabilitadas para o encontro com a diferença, ampliando o desuso e atrofiamento da negociação e diálogo - a conversa, muitas vezes, não chega se quer a ser estabelecida, como Pedro aponta.

A experiência discursiva própria da amizade, na qual o diálogo configura-se como relação de abertura aos outros, vai se perdendo cada vez mais - tal como Bauman (2004) adverte. Não obstante, segundo Arendt (2001), o que nos faz humanos é precisamente o fato de compartilharmos o mundo com outros, a "abertura aos outros" é "a precondição da 'humanidade' em qualquer sentido dessa palavra..." (Arendt, 1993, citado por Bauman, 2004, p. 177). O compartilhamento do mundo através do diálogo informa a qualidade especificamente humana que é a de ser um ser político que só pode ser entendido em relação com os outros em um mundo compartilhado.

\section{A mercantilização dos vínculos humanos e a destruição deliberada dos coletivos}

Na medida em que o espaço discursivo e de experimentação da amizade ilumina a solidariedade humana, a palavra amizade ou amigo tem sido deturpadamente apropriada pelos agenciamentos neoliberais como o 'projeto amigos da escola', ou, ainda, os programas de crédito “amigo" veiculados pela televisão - vinculados mais a práticas tutelares do que à promoção de autonomia os quais não correspondem, de maneira alguma, à beleza da generosidade do gesto solidário o qual possibilita o exercício político de ver o mundo a partir do lugar do outro, permitindo a irrupção do imprevisto. $\mathrm{O}$ crédito que se propõe "amigo" não se associa em nada com o encanto da gratuidade do gesto de solidariedade nos laços de amizade, já que ele pressupõe a cobrança de juros exorbitantes; e o projeto amigos da escola articula-se, estreitamente, com a lógica do voluntariado e não com movimentos que visam à emancipação política. Essa distorção semântica articula-se ao processo de subordinação da cultura e da subjetividade ao registro econômico, como adverte Silva Júnior (2004).

Essa apropriação perversa da semântica da amizade pelo mercado capitalista que tem como pressuposto imperativo o lucro a qualquer custo, vincula a venda de uma série de produtos à amizade e à palavra amigo. Dentro da lógica contemporânea de consumo que privilegia a 'dimensão imaterial' do produto, mais do que o objeto em si mesmo, o que se vende é a qualidade imaterial dos afetos, perceptos, sensações, sentimentos - que são articulados aos artigos de consumo. Esse processo de associação da afetividade humana ao consumo é intrínseco ao advento de sutilização inédita das modalidades de controle social, advertido por Bourdieu (1998).

Bauman (2004) comentando sobre esse advento de apropriação de idéias e sentimentos que são associados aos produtos destinados ao consumo, alerta que o mercado capitalista ao transformar vínculos humanos e pessoas em mercadorias, tem promovido o esfacelamento da solidariedade humana e das habilidades de sociabilidade que não são atributos de uso e nem de comercialização. Segundo o autor é precisamente porque vivemos num mundo em que a solidariedade e ajuda - noções estranhas e abominadas pela lógica e prática econômica - estão escassas que o mercado tenta insistentemente transformálas em categorias compráveis, às quais se tem acesso através do ato de comprar e consumir. O mercado pretende, incessantemente, transformar a amizade e laços humanos em produtos postos à venda, transformados em objetos os quais podem ser comprados pelo consumo - lógica perversa do mercado que vê oportunidade de lucro onde existe necessidade humana, como informa Bauman (2004): 
A necessidade de solidariedade parece suportar as agressões do mercado e sobreviver a elas - mas não porque o mercado deixe de tentar. Onde há necessidade há chance de lucro - e os especialistas em marketing levam sua engenhosidade ao limite para indicar maneiras de adquirir em lojas a solidariedade, o sorriso amigo, o convívio ou a ajuda no momento de necessidade. Constantemente têm êxito e constantemente fracassam. Sucedâneos comercializados não podem substituir vínculos humanos. Em sua versão à venda, os vínculos se transformam em mercadorias, ou seja, são transportados para um outro domínio, governado pelo mercado, e deixam de ser os tipos de vínculo capazes de satisfazer a necessidade de convívio e que só nesta podem ser concebidos e mantidos vivos. Não pode ter êxito a caçada movida pelo mercado ao capital descontrolado que se esconde na sociabilidade humana (Bauman, 2004, p. 91).

Vários autores, entre eles, Bauman (2004), Bourdieu (1998), Sennett (1988) etc. - têm atentado para essa ressemantização da totalidade das relações sociais, advinda das novas estratégias discursivas voltadas para produção de um discurso essencialmente mascarado de relações de exploração. Essa nova modalidade discursiva e de práticas de controle social da política de globalização que transforma vínculos humanos, entre estes a amizade, em objetos a serem consumidos tem produzido o esmorecimento da solidariedade.

Ao transformar pessoas e relacionamentos em produtos de consumo, os agenciamentos neoliberais proporcionam a ampliação do estilhaçamento da solidariedade, transportando a lógica de mercado consumista - que impõe uma velocidade cada vez maior no uso dos objetos, que se tornam fácil e rapidamente descartáveis pelo imperativo da substituição frenética dos modelos e versões mais atualizados - para os laços e parcerias humanos que, além de já estarem esfacelados, em estado de liquefação, passam a adquirir essa dimensão de descartabilidade, como constatado por Bauman $(2001,2004)$.

O desvanecimento das habilidades de sociabilidade é reforçado e acelerado pela tendência, inspirada no estilo de vida consumista, a tratar os outros seres humanos como objetos de consumo e a julgá-los, segundo o padrão desses objetos, pelo volume de prazer que provavelmente oferecem e em termos de seu "valor monetário". Na melhor das hipóteses, os outros são avaliados como companheiros na atividade essencialmente solitária do consumo, parceiros nas alegrias do consumo, cujas presenças e participação ativa podem intensificar esses prazeres. Nesse processo, os valores intrínsecos dos outros como seres humanos singulares (e assim também a preocupação com eles por si mesmos, e por essa singularidade) estão quase desaparecendo de vista. A solidariedade humana é a primeira baixa causada pelo triunfo do mercado consumidor (Bauman, 2004, p. 96).

Quando se reduz o outro, quando se é indiferente a este na busca pela satisfação e segurança individual, quando corações encontram-se amortecidos, é o sentido da política que se esvai; quando a solidariedade inter-humana esmorece politicamente, a necessidade de ligação humana dilacera-se.

O espaço discursivo e de experimentação da amizade promove vínculos de solidariedade entre amigos, numa relação em que a presença imediata do outro nos impele e proporciona deslocamentos e novas experimentações. As histórias relatadas destacam relações em que os sujeitos são impelidos e desafiados a agir, a ajudar e trazer alívio em situações em que esse outro sofre e precisa de auxílio. Não obstante, é válido destacar que quando questionados sobre as relações no trabalho os sujeitos ressaltam relações de competição que geram práticas individualistas e de isolamento social, imperativos do registro econômico. Além disso, poucas foram as histórias em que a solidariedade foi mobilizada por grupos, por uma coletividade, o que informa a condição de fragilidade e debilidade das parcerias, constatada por Bauman $(2001,2004)$.

A maioria dos sujeitos afirma ter amigos na cooperativa em que trabalham, no entanto, destacam relações competitivas, num ambiente de "panelinhas" onde nem sempre se é compreendido. Os sujeitos afirmam que, em geral, existe abertura para negociação e diálogo, por ser uma relação de trabalho democrática, na qual não existe autoridade e as decisões são tomadas coletivamente nas reuniões dos cooperados, sendo também possível resolver problemas no dia-a-dia, através de conversas. Porém, apontam que nem todos são considerados amigos, sendo alguns considerados apenas como colegas de trabalho, configurando um espaço de afastamento entre as pessoas que impossibilita, muitas vezes, o diálogo e que produz um sentimento de "estar sufocado", conforme Pedro afirmou. O registro econômico que impõe o sucesso a qualquer custo pautado na competitividade e relações individualistas mobilizadas exclusivamente por interesses individuais, incompatíveis com a consideração e cuidado do outro, aparece nos discursos através de relações competitivas em que um quer ser melhor que o outro e de intrigas pessoais:

Porque, é assim, em todo lugar sempre tem um que quer subir e pisar na cabeça dos outros. Tem muita relação de competição. Atrapalha porque a pessoa acaba sendo falsa com você, você fala uma coisa pra pessoa, seja do escritório, seja quem for, então você acha que você pode confiar e não pode, quando você menos espera a bomba explode, se você não tiver um argumento não falar o que foi falado realmente você acaba dançando (Gabriel). 
Existe, mas como no serviço, tem sempre um querendo ser melhor que o outro, que nem, conseguir queimar o outro, pra poder falar que é melhor, mostrar, mas sempre tem uns que dão para fazer amizade de verdade... (Mateus).

Pode, agora na cooperativa não tem isso não, a cooperativa tem uma pressão desgraçada em cima das pessoas, principalmente as dos que trabalham no campo, entendeu, controla o seu horário, quer controlar sua vida, até sua vida pessoal as pessoas querem controlar, entendeu, se mete na sua vida, faz conversinha, fofoquinha, buxixo de coisas que não tem nada a ver só pra ver você mal com a outra pessoa, entendeu, eu estou falando isso, porque eu sinto isso na minha pele, entendeu (Rosa).

Os relatos revelam as dificuldades e contradições no processo coletivo de sedimentação da cultura solidária própria do cooperativismo, na qual o cultivo da solidariedade no cotidiano da cooperativa representa um grande desafio. Segundo Oliveira (2004), muitos são os obstáculos ao processo de formação de projeto coletivo das cooperativas, não é tarefa fácil mudar e assimilar rapidamente novas formas de relacionamentos e ação. O modelo capitalista dominante imprime modos individualistas e competitivos de se relacionar, portanto, o caráter processual é inerente à formação da cultura solidária nas cooperativas - o que requer uma longa e difícil jornada para que o cooperativismo ganhe viço, como destaca Oliveira.

Essas relações competitivas mobilizadas por interesses individuais são impelidas pelos imperativos econômicos que visam cada vez mais imprimir o individualismo e práticas de descuido do outro, dentro da lógica do "cada um por si' que dá o tom das ações mobilizadas estritamente pelo crescimento particular, dilacerando as parcerias pautadas pelo engajamento coletivo. Essas relações de competição impelidas pela busca do sucesso particular produzem práticas violentas de desconsideração e descuido do outro, nesta procura incessante de "ser melhor que o outro" que os sujeitos destacam. Esse imperativo de êxito pessoal que os agenciamentos neoliberais imprimem gera o afastamento das pessoas e práticas de exclusão do outro nessa busca incessante que privilegia o bem estar pessoal e não coletivo, produzindo um isolamento social e solapamento dos vínculos solidários. O individualismo instaurado pelo registro econômico visa precisamente destruir a condição política da reunião não violenta dos homens, advertida por Arendt (2001), promovendo práticas de descaso e descompromisso com outro que desestimula Rosa a querer lutar por um bem coletivo, pela cooperativa. As atitudes individualistas que levam à negligência da condição do outro, promovem relações de não confiança e de desrespeito pelo outro que fazem Rosa sentirse 'machucada' e também a impossibilita de participar de eventos e encontros políticos que trariam benefícios coletivos, possibilitando o crescimento da cooperativa.
Bauman (2004) constata queé, precisamente, esse afrouxamento dos laços humanos, inclusive a amizade, que os agenciamentos neoliberais visam alcançar ao transformar os vínculos em objetos descartados tão rapidamente quanto como foram consumidos. Segundo ele, a contemporânea articulação das relações humanas à lógica da descartabilidade e alterabilidade dos produtos destinados ao consumo, a morte nos separe" seja cada vez mais sentido como relação que deve ser evitada a qualquer custo, promovendo um afastamento entre as pessoas que são estimuladas a esquivar-se e a acreditar que o investimento em parcerias representa um risco enorme. Os vínculos humanos transformados em objetos de consumo passam a ser valorizados pelos novos atributos de conveniência de uso e descartabilidade, próprios do ato de consumir - processo que privilegia os 'relacionamentos rápidos', de pouca durabilidade, que não implicam engajamento e esforço fazendo com que o vínculo de comprometimento com outro seja sentido como condição opressiva e maçante.

Estas práticas que visam destroçar a solidariedade podem ser observadas nos relatos dos sujeitos que mencionam relações em que o descaso pelo que o outro fala, a desconsideração da condição do outro, apontam atitudes individualistas incompatíveis com o gesto solidário da amizade de escuta acolhida e respeitosa:

... aqui já mesmo muitos casos a pessoa às vezes está errada, na minha concepção, no meu entendimento ela está errada, e bate o pé e não deixa você falar, ela está certa e o que é errado pra ela está certo e bola pra frente que ela pensa que é assim, eu não posso fazer nada, e não dar oportunidade de você se explicar, até de você ter um argumento, então tenho esta certa repreensão de alguns, no trabalho, não muitos, algumas pessoas, mas com as pessoas assim que eu converso, amigos que eu converso sempre tem, tipo fala que eu te escuto e sempre foi assim, as pessoas que eu conheço mesmo, meus amigos, são assim (Pedro).

... se as pessoas se unissem mais, se preocupassem mais realmente com a cooperativa e não com a vida pessoal das pessoas, as coisas andavam, um ajudando o outro, porque tem gente que quer ajudar $e$ a pessoa não deixa, ela coloca uma barreira ali que não deixa, e você fica impossibilitado de conseguir (Rosa).

Hoje, eu acho, não todas, mas há uma grande falta de respeito uma para com as outras, sabe, e falta, uma das coisas importantes que falta na sociedade é diálogo, se as pessoas se preocupassem mais em conversar, em ter informações, aprender umas com as outras seria mais fácil de se viver, mas nem todo mundo se dispõe a fazer isso (Gabriel).

Com o esmorecimento da solidariedade, esvaecem-se as necessidades sociais de uns pelos outros, que nos humaniza; dilui-se a dimensão política de estarmos juntos compartilhando o mundo - o que nos torna humanos como 
ilumina Arendt (1993, 2001). Em tempos de esvaecimento das parcerias e laços solidários, em que o imperativo máximo torna-se a busca por sucesso particular em detrimento do tecido afetivo que tem sido deliberadamente destruído, urge voltarmos atenção para a intersubjetividade, para a amizade. Pensar a amizade como vínculos de abertura ao outro representa um convite desafiador a lançarmonos em relações que não suprimam a alteridade. Pensar a possibilidade da amizade como espaço de experimentação capaz de irromper formas fixas de subjetividade e sociabilidade, constituindo uma forma de resistência política, representa um convite à alteridade, à consideração dos outros como estranhos, numa relação experimental designada pelo compromisso irreversível com o outro.

\section{Notas}

1 Todas as entrevistas foram gravadas, com prévia autorização dos sujeitos, os quais também assinaram termo de consentimento livre informado que garante a não identificação pessoal dos sujeitos e da instituição.

\section{Referências}

Arendt, H. (1993). A dignidade da política: Ensaios e conferências (3. ed., H. Martins, Trad.). Rio de Janeiro, RJ: Relume Dumará.

Arendt, H. (2001). A condição humana (10. ed., R. Raposo, Trad.). Rio de Janeiro, RJ: Forense Universitária.

Bauman, Z. (2001). Modernidade líquida (P. Dentzien, Trad.). Rio de Janeiro, RJ: Jorge Zahar.

Bauman, Z. (2004). Amor líquido: Sobre a fragilidade dos laços humanos (C. A. Medeiros, Trad.). Rio de Janeiro, RJ: Jorge Zahar.

Bloom, A. (1993). Amor e amizade (A P. Curado, Trad.). Lisboa, Portugal: Europa-América.

Bosi, E. (2003). O tempo vivo da memória: Ensaios de Psicologia Social (2. ed.). São Paulo, SP: Ateliê.

Bourdieu, P. (1998). Contrafogos: Táticas para enfrentar a invasão neoliberal (L. Magalhães, Trad.). Rio de Janeiro, RJ: Jorge Zahar.

Bruner, E. M. (1986). Ethnography as narrative. In V. W. Turner \& E. M. Bruner. The Anthropology of experience (pp. 139-155). Chicago: University of Illinois.

Derrida, J., \& Dufourmantelle, A. (2003). Anne Dufourmantelle convida Jaques Derrida a falar da hospitalidade (A. Romane, Trad.). São Paulo, SP: Escuta.

Geertz, C. (1989). A interpretação das culturas. Rio de Janeiro, RJ: Livros Técnicos e Científicos.
Oliveira, P. S. (2004). Cultura solidária em cooperativas: Projetos coletivos de mudança de vida. Tese de Livre-docência não-publicada, Instituto de Psicologia, Departamento de Psicologia Social e do Trabalho, Universidade de São Paulo, SP.

Sennett, R. (1988). O declínio do homem público: As tiranias da intimidade (L. A. Watanabe, Trad.). São Paulo, SP: Companhia das Letras.

Silva, N. da, Jr. (2004). Sobre a re-codificação mercantil do sofrimento. Prefácio. In M. S. Bolguese. Depressão \& Doença nervosa moderna (pp. 9-14). São Paulo, SP: Via Lettera.

Singer, P. (2002). Introdução à economia solidária. São Paulo, SP: Editora da Fundação Perseu Abramo.

Lívia Godinho Nery Gomes é Doutoranda em Psicologia Social na Universidade de São Paulo (USP), com bolsa da Fundação de Amparo à Pesquisa do estado de São Paulo (FAPESP), Mestre em Psicologia Social pela Universidade de São Paulo, Psicodramatista.

liviagng@ig.com.br

Nelson da Silva Junior é Psicanalista, Doutor pela Universidade Paris VII, Professor Livre Docente do Departamento de Psicologia Social e do Trabalho do Instituto de Psicologia da USP, Professor Visitante da Université de Bretagne Occidentale, Professor do Curso de Psicanálise do Instituto Sedes Sapientiae, membro do Departamento de Psicanálise do Instituto Sedes Sapientiae e da Associação Universitária de Pesquisa em Psicopatologia Fundamental. Autor dos livros: Le fictionnel en psychanalyse. Une étude à partir de l'œuvre de Fernando Pessoa. Villeneuve d'Asq: Presses Universitaires du Septentrion, 2000, e Lógica na razão e desrazão, Casa do Psicólogo, no prelo. Endereço para correspondência: Alameda Iraé, 620, conjunto 16, São Paulo, SP, 04075-000. nesj@terra.com.br

\section{Sobre a amizade em tempos de solidão}

Lívia Godinho Nery Gomes e Nelson da Silva Junior Recebido: 11/05/06

$1^{\text {a }}$ revisão: $17 / 10 / 06$

$2^{\mathrm{a}}$ revisão: 19/01/07

$3^{\mathrm{a}}$ revisão: 06/03/07

Aceite final: 19/03/07 